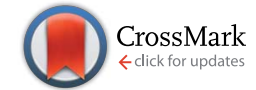

Cite this: RSC Adv., 2017, 7, 3343

\title{
Thiol-ene chemistry of vegetable oils and their derivatives under UV and air: a model study by using infrared spectroscopy and mass spectrometry $\dagger$
}

\author{
Yu Hui Zhao, ${ }^{a}$ Sébastien Hupin, ${ }^{b}$ Laurence Lecamp, ${ }^{\text {a }}$ Daniela Vuluga, ${ }^{a}$ \\ Carlos Afonso, ${ }^{\mathrm{b}}$ Fabrice Burel $^{\mathrm{a}}$ and Corinne Loutelier-Bourhis ${ }^{\mathrm{b}}$
}

\begin{abstract}
Herein, a model study of the photoinitiated thiol-ene reaction was carried out on unsaturated fatty methyl esters at room temperature and without photoinitiator. Reaction kinetics were monitored by FTIR spectroscopy and reaction products were identified by high resolution mass spectrometry coupled to ion mobility spectrometry. This set of analytical tools enabled us to highlight the concomitance of fatty double bond oxidation and thiol-ene addition when such a formulation was exposed to UV radiation. Indeed, thiol-ene adducts were identified on fatty moieties oxidized or not, without prevalence of one reaction over the other: photoinitiated thiol-ene addition could occur on preoxidized products, and photooxidation could occur on thiol-ene adducts. However, the presence of oxidized fatty products such as peroxides and zwitterionic species was proved to be favourable to the photocrosslinking of fatty coatings by thiol-ene addition.
\end{abstract}

Received 21st October 2016

Accepted 15th December 2016

DOI: $10.1039 / c 6 r a 25633 c$

www.rsc.org/advances

Several works have already mentioned the role of oxygen in

\section{Introduction}

Photoinitiated thiol-ene reaction has been extensively studied in recent years and is mainly used to functionalize fatty molecules. However, because of the weak reactivity of fatty double bonds, particular conditions are necessary to achieve a good reaction conversion: low temperature, high thiol/ene ratios $(>4)$, long reaction time (several hours to days), and use of photoinitiator. ${ }^{1,2}$ Until today, only a few materials have been prepared directly from native oil. ${ }^{3}$ In a previous work, we have shown that crosslinked fatty coatings could be obtained from linseed oil using the photoinitiated thiol-ene reaction (Fig. 1). ${ }^{4}$

The low thickness of these coatings has enabled to reach an optimal conversion of double bonds (higher than $80 \%$ ) after 20 min irradiation under air in the presence of only 0.5 equivalent of thiol and without photoinitiator. Furthermore, crosslinking was observed even when a monothiol was used. All these unusual results have led us to assume the existence of concomitant intermolecular reactions during the irradiation step, taking place together with the classical thiol-ene addition. The participation of oxygen during the photoinitiated thiol/ene addition has been especially highlighted.

${ }^{a}$ Normandie Univ, UNIROUEN, INSA Rouen, CNRS, PBS, 76000 Rouen, France. E-mail: laurence.lecamp@insa-rouen.fr

${ }^{b}$ Normandie Univ, UNIROUEN, INSA Rouen, CNRS, COBRA, 76000 Rouen, France

$\uparrow$ Electronic supplementary information (ESI) available. See DOI: $10.1039 / \mathrm{c} 6 \mathrm{ra} 25633 \mathrm{c}$ the thiol-ene addition and detected numerous unclear side products..$^{5-7}$ One of the key advantages of the thiol-ene addition is its high ability to overcome the oxygen inhibition. Indeed, formation of peroxyl radicals does not inhibit the hydrogen abstraction from thiol groups to form thiyl radicals. Besides, several works have also noticed the oligomerization of triglycerides during the thiol-ene addition under UV. ${ }^{6,8}$ Until now, these results have been explained by a possible propagation of the radical reaction to fatty double bonds. Indeed, such a reaction has been highlighted for 1,4-polybutadiene which exhibited quite similar double bond structures compared to fatty acids. ${ }^{9}$

This work aims to investigate the nature of these concomitant reactions and to explain how triglycerides molecules could be crosslinked with a monothiol in large default in respect to the fatty double bond amount. Due to the complexity of the linseed oil composition (fatty moieties with various unsaturation degrees), ${ }^{10}$ the study was performed on monounsaturated fatty monoesters as model molecules. This study first focused in studying the photo-oxidation of methyl esters. In a second part,

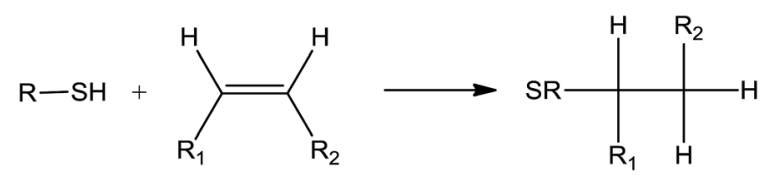

Fig. 1 Schematic depiction of thiol-ene addition. 
the photoinitiated thiol-ene reaction under air was investigated. The structural analyses of the different reaction products was carried out using electrospray ionization-ion mobility spectrometry-tandem mass spectrometry (ESI-IMS-MS/MS) and gas chromatography-mass spectrometry (GC-MS).

\section{Experimental}

\section{Materials}

Oleic acid (OA, 90\%), elaidic acid (EA, 99\%) and methyl stearate (MeS, 99\%) obtained from Sigma Aldrich were used as fatty model molecules. Dodecanethiol (DT, 98\%) obtained from Merck-Schuchardt was used as monothiol monomer. Deuterated chloroform and sulfuric acid (98\%) were purchased from VWR. All materials were used as received. Any deoxygenation procedure was carried out on samples before irradiation.

\section{Preparation of fatty methyl esters}

Into a $50 \mathrm{~mL}$ round bottom flask fitted with a magnetic stirrer and a reflux condenser, were introduced oleic or elaidic acid $\left(5 \mathrm{~g}, 17 \mathrm{mmol}\right.$ ) and methanol $(30 \mathrm{~mL}) \cdot \mathrm{H}_{2} \mathrm{SO}_{4}$ (about $0.3 \mathrm{mmol}$ ) was then added drop by drop. The mixture was heated to boiling point and reflux for $24 \mathrm{~h}$. After phase separation, the alcoholic phase was washed with diethyl ether $(2 \times 30 \mathrm{~mL})$. All the lipophilic phases were then collected, washed with water and dried with $\mathrm{MgSO}_{4}$. The solvent was evaporated under vacuum affording a colorless liquid. Another derivation method was tested using $\mathrm{BF}_{3} / \mathrm{CH}_{3} \mathrm{OH}$, as previously described. ${ }^{11}$

\section{Thiol-ene formulation}

2 mol of methyl oleate or elaidate was mixed with 1 mol of dodecanethiol ("thiol" to "ene" ratio of 0.5 ). No solvent was added. Reagents were stirred for 2 min before irradiation.

\section{Analytical techniques}

${ }^{1} \mathrm{H}$ NMR analyses were carried out on a Bruker $300 \mathrm{MHz}$ spectrometer at room temperature. The chemical shifts are given in ppm relative to trimethylsilane (TMS) used as external reference. Samples were prepared as follows: $10 \mathrm{mg}$ of product in $0.4 \mathrm{~mL}$ of $\mathrm{CDCl}_{3}$.

Fourier Transform Infra-Red (FTIR) spectra were performed on a Vertex 70 Bruker spectrometer equipped with an ATR accessory (ATR MK II Golden Gate Specac, Eurolabo). A drop of the sample was applied to the horizontal ATR crystal and then covered or not by a polyethylene film. The presence of the polyethylene film (laminated conditions) allows avoiding the contact of the sample with air. Samples were exposed to an UV light coming from a polychromatic $\mathrm{Hg}$-Xe lamp (Hamamatsu LC8 $-I_{0}=120 \mathrm{~mW} \mathrm{~cm}{ }^{-2}$ at $365 \mathrm{~nm}$ ) for $20 \mathrm{~min}$ at $30{ }^{\circ} \mathrm{C}$. IR spectra were simultaneously recorded versus irradiation time. Double bond consumption was determined by following the absorption peak at $3010 \mathrm{~cm}^{-1}$ for the cis configuration alkene. Carbonyl group at $1640 \mathrm{~cm}^{-1}$ was used as peak reference. The absorbance measured for each functional group was determined by the area $(A)$ of the corresponding absorption peak. The double bond conversion was then calculated using the ratios of the double bonds absorbance $\left(A^{3010}\right)$ to the reference absorbance $\left(A^{1640}\right)$ during irradiation, as follows: ${ }^{12}$

$$
\text { Conversion }(\%)=\frac{\frac{A_{0}{ }^{3010}}{A_{0}{ }^{1640}}-\frac{A_{t}{ }^{3010}}{A_{t}{ }^{1640}}}{\frac{A_{0}{ }^{3010}}{A_{0}{ }^{1640}}} \times 100
$$

where $A_{0}$ is the initial area and $A_{t}$ is the area of the peak at $t$ time. The variation of the $\mathrm{OH}$ band absorbance $\left(A_{\text {final }}-A_{\text {initial }}\right)$ at 3500 $\mathrm{cm}^{-1}$ was also monitored versus time.

ESI-IMS-MS(/MS) experiments were performed using a Waters Synapt G2 hybrid quadrupole/time of flight HDMS instrument equipped with an ESI LockSpray ${ }^{\mathrm{TM}}$ source and a travelling-wave ion mobility spectrometry (TWIMS) cell consisting of three travelling wave-enabled stacked ring ion guides, as previously described. ${ }^{13,14}$ MassLynx 4.1 and DriftScope 2.2 softwares (Waters, Manchester, UK) were used for the spectra acquisition and treatment. The sample solutions were infused into the source with a syringe pump (Cole-Palmer, Vernon Hills, Illinois, USA) set at a flow-rate of $3 \mu \mathrm{L} \mathrm{min}^{-1}$. The ESI source parameters were set as followed: capillary voltage; $3 \mathrm{kV}$, sample cone voltage; $40 \mathrm{~V}$, extraction cone voltage; $5 \mathrm{~V}$, source temperature; $90{ }^{\circ} \mathrm{C}$, desolvation temperature, $250{ }^{\circ} \mathrm{C}$; desolvation gas flow $\left(\mathrm{N}_{2}\right), 500 \mathrm{~L} \mathrm{~h}^{-1}$. MS and MS/MS experiments were acquired over a range of 50 to $2000 \mathrm{~m} / \mathrm{z}$ (1 s scan time and $0.02 \mathrm{~s}$ interscan delay) in either ' $\mathrm{V}$ ' resolution mode (resolution 20000 FWHM) or ' $\mathrm{W}$ ' resolution mode (resolution 40000 FWHM) (when necessary for accurate mass measurements). Calibration was performed with sodium formate cluster ions. Leucine enkephalin ( $2 \mathrm{ng} \mu \mathrm{L}^{-1}$ ) was used as the lock mass and infused ( $\left.3 \mu \mathrm{L} \mathrm{min}{ }^{-1}\right)$ using an independent reference spray via the LockSpray ${ }^{\mathrm{TM}}$ interface which was operated at a reference scan frequency, lock spray capillary and collision energy of $10 \mathrm{~s}$, $3 \mathrm{kV}$ and $4 \mathrm{eV}$, respectively. $1 \mu \mathrm{L}$ of a $0.1 \mathrm{~mol} \mathrm{~L}^{-1} \mathrm{LiI}$ solution was added into $500 \mu \mathrm{L}$ sample solution to force the formation of [M $+\mathrm{Li}]^{+}$ions and to avoid any ambiguity between $[\mathrm{M}+\mathrm{Na}]^{+},[\mathrm{M}+$ $\mathrm{K}]^{+}$and oxidized species.

For MS/MS experiments, the $[\mathrm{M}+\mathrm{Li}]^{+}$precursor ion was selected by the quadrupole mass analyzer within a $1 \mathrm{~m} / z$ unit window and then dissociated in the transfer collision cell (30 eV) using Ar as the collision gas.

Elemental compositions (MS and MS/MS modes) were proposed from the accurate mass measurements and taking into account the isotope predictive filtering value (i-FITTM) given for each possible elemental composition.

For IMS-MS/MS, $\mathrm{N}_{2}$ was used as IMS gas flow (90 $\mathrm{mL} \mathrm{min}^{-1}$ ) whereas helium was used as cell gas flow $\left(180 \mathrm{~mL} \mathrm{~min}^{-1}\right)$. The wave height was $40 \mathrm{~V}$, the wave velocity $650 \mathrm{~m} \mathrm{~s}^{-1}$ and the IMS wave delay $450 \mu \mathrm{s}$. The precursor ions were mass-selected using the quadrupole $(1 \mathrm{~m} / \mathrm{z}$ unit window), then separated in the mobility cell and finally dissociated into product ions that were analysed using the TOF mass spectrometer. Such analysis is helpful to investigate the relationship between product and precursor ions.

GC-MS analyses were recorded using a time-of-flight mass spectrometer JEOL GC-AccuTOF (Tokyo, Japan) equipped with 
an Agilent 7890A gas chromatograph. Separations were carried out using a Zebron Z5-MSi capillary column $(0.25 \mathrm{~mm}$ i.d. $\times 30$ $\mathrm{m}, 0.25 \mu \mathrm{m}$ film thickness; Phenomenex). The carrier gas was helium and the flow rate was $0.8 \mathrm{~mL} \min ^{-1}$ (constant flow mode). The column temperature programming started at $60{ }^{\circ} \mathrm{C}$ (1 min holding time) ramped to $350^{\circ} \mathrm{C}$ at $10^{\circ} \mathrm{C} \mathrm{min}{ }^{-1}$, then the temperature was held at $350^{\circ} \mathrm{C}$ for $20 \mathrm{~min}$. The inlet and line temperatures were $290^{\circ} \mathrm{C}$ and $280^{\circ} \mathrm{C}$, respectively. Injections of $1 \mu \mathrm{L}$ were carried out in either split $(1: 10)$ or splitless mode. Electron ionization (EI) mass spectra were recorded using an ionizing voltage of $70 \mathrm{eV}$, ionizing current of $300 \mu \mathrm{A}$, emission current of $355 \mu \mathrm{A}$. The source temperature was $260{ }^{\circ} \mathrm{C}$. The detector voltage was $2200 \mathrm{~V}$ and the instrument mass resolution was 8000 (FWHM). The mass spectra were recorded over a range of 35 to $800 \mathrm{~m} / \mathrm{z}$.

\section{Results and discussion}

Two monounsaturated fatty esters were studied. Methyl oleate (MO) and methyl elaidate (ME) were prepared by methylation of the corresponding fatty acids, as described in the Experimental section. FTIR and ${ }^{1} \mathrm{H}$ NMR analyses of the obtained products revealed that oleic acid-based ester was actually composed of 90 mol\% of methyloctadec-9(Z)-enoate (or cis-methyl oleate (MO)) and $10 \mathrm{~mol} \%$ of methyloctadecadi-9(Z),12(Z)-enoate (or 9-cis,12cis-methyl linoleate (ML)) while only a monounsaturated ester was detected in the methyl elaidate (ME) sample with fatty double bond in trans configuration (Fig. 2). ESI-MS analyses of these products, after adding LiI $\left(0.1 \mathrm{~mol} \mathrm{~L}^{-1}\right)$ in the sample solution to promote lithium adduct formation, show the expected $[\mathrm{M}+\mathrm{Li}]^{+}$ion (with $\mathrm{M}=\mathrm{ME}$ or $\mathrm{MO}$ ) at $\mathrm{m} / z$ 303.2874 (Fig. SI.1a †). However, additional lithiated ions were also detected. The most abundant of them were the $\mathrm{m} / \mathrm{z} 351.3084$ and $\mathrm{m} / \mathrm{z} 379.3038$ ions. According to their accurate mass measurements (HRMS), these ions could correspond to the $\mathrm{C}_{20} \mathrm{H}_{40} \mathrm{LiO}_{4}$ and $\mathrm{C}_{21} \mathrm{H}_{40} \mathrm{LiO}_{5}$ elemental compositions, i.e. $[\mathrm{M}+\mathrm{O}$ $\left.+\mathrm{CH}_{3} \mathrm{OH}+\mathrm{Li}\right]^{+}$and $\left[\mathrm{M}-2 \mathrm{H}+\mathrm{O}+2 \mathrm{CH}_{3} \mathrm{O}+\mathrm{Li}\right]^{+}$(with $\mathrm{M}=\mathrm{ME}$ or MO), respectively. Note that $\mathrm{m} / z$ 379.3038, more abundant for $\mathrm{MO}$, can also correspond to $\left[\mathrm{ML}+\mathrm{O}+2 \mathrm{CH}_{3} \mathrm{OH}+\mathrm{Li}\right]^{+}$. These species are oxidation and methoxidation products formed

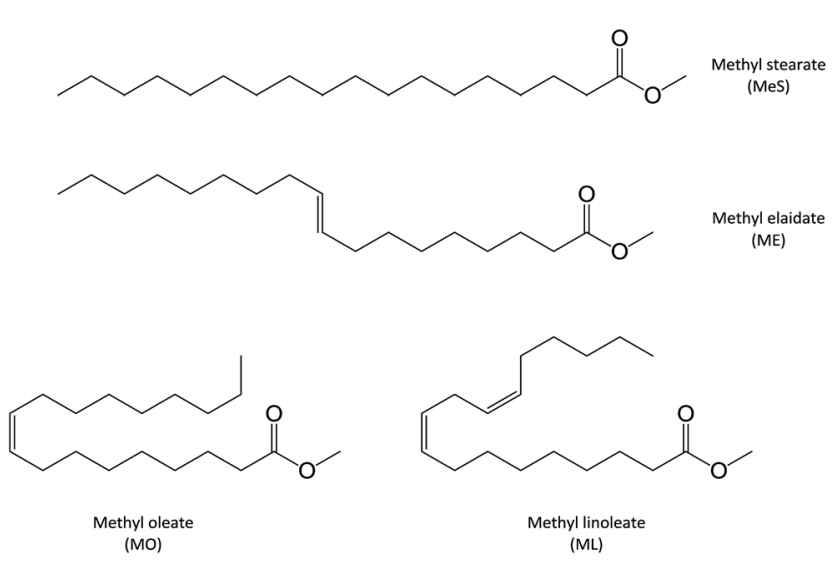

Fig. 2 Chemical formula of the model molecules. during the esterification process (see Fig. SI.1b in ESI $\dagger$ and Table 1) ${ }^{15,16}$ It could be noticed that these side products were formed whatever the derivation method used (e.g. $\mathrm{MeOH} / \mathrm{H}_{2} \mathrm{SO}_{4}$ or $\left.\mathrm{BF}_{3} / \mathrm{MeOH}\right)$ and did not seem to have influence on the studied photochemical reactions. Indeed, these reactions were carried out on a sample of pure commercial MO and led to mass spectra similar to those presented in this study (data not shown). Besides, additional low abundant $\mathrm{m} / \mathrm{z} 319.2824$ ion was also detected which could correspond to lithiated monooxidized fatty ester $[\mathrm{M}+\mathrm{O}+\mathrm{Li}]^{+}$(with $\mathrm{M}=\mathrm{ME}$ or MO) (Table 1). These oxidation products are usually encountered for unsaturated fatty esters. ${ }^{18-32}$ The other low-abundant ions detected on the mass spectra were either non covalent aggregates of fatty esters or contaminants presents in the solvent. The last ones were also observed when solvent was solely infused.

Once the fatty esters have been characterized, the study of their behavior under UV irradiation was carried out in a first step. The reaction of each fatty ester with dodecanethiol was investigated in a second step.

\section{Photo-oxidation of fatty esters}

Fatty esters were separately irradiated at $30{ }^{\circ} \mathrm{C}$ under air or laminated conditions. The reaction was monitored in real time by infrared spectroscopy. The photo-oxidation kinetic study of methyl oleate is reported in Fig. 3.

Surprisingly, Fig. 3a shows a slow but regular fatty double bond consumption that reached $40 \%$ after 20 min of irradiation in aerated conditions and 30\% when samples were covered by a PE film (laminated conditions). At the same time, an absorption band at $3500 \mathrm{~cm}^{-1}$ appeared from the beginning of the irradiation (Fig. 3b), which could be attributed to hydroxyl and/or hydroperoxide groups. According to literature, ${ }^{17-21}$ even in fresh solutions, oxidized products of fatty moieties are present. These products could result from reaction between fatty radicals and ${ }^{3} \mathrm{O}_{2}$ biradical species present in the air. When exposed to UV-A and UV-B radiations (between 280 to $400 \mathrm{~nm}$ ), those oxidized molecules could decompose into radicals and react with surrounding fatty molecules (HX) to form new fatty radicals and fatty hydroperoxides (Fig. 4 - type I photooxidation). However, the absorbance curve variations were different depending on the experimental irradiation conditions (Fig. 3b). Indeed, after similar increasing kinetics during the first $100 \mathrm{~s}$ irradiation, the reaction rate slowed down and then decreased for fatty ester in laminated film, while a plateau was reached after $500 \mathrm{~s}$ irradiation for sample in the presence of air. Regensburger has recently proved that the decomposition of hydroperoxides under UV-A and UV-B radiations could generate ${ }^{1} \mathrm{O}_{2}$ according to the so-called Russell mechanism. ${ }^{20,21}$ The singlet oxygen could then induce a type II photo-oxidation of fatty double bonds (Fig. 4). Hence, under UV radiation, the higher the ${ }^{1} \mathrm{O}_{2}$ generation, the higher the hydroperoxide formation and vice versa. But, in laminated conditions, the lack of ${ }^{3} \mathrm{O}_{2}$ and the end of ${ }^{1} \mathrm{O}_{2}$ stock resulting from the photodecomposition of hydroperoxides could explain the disappearance of $\mathrm{OH}$ groups in the fatty sample over time. In aerated conditions, a competition between the photolysis and the 
Table 1 Accurate mass measurements, elemental composition and identification of the different ion species observed in reaction media

\begin{tabular}{llllll}
\hline Ion $(\mathrm{m} / z)$ & Experimental $(\mathrm{m} / \mathrm{z})$ & Calculated $(\mathrm{m} / \mathrm{z})$ & $\Delta M(\mathrm{ppm})$ & Elemental composition & Identification \\
\hline 301 & 301.2719 & 301.2713 & -2.0 & $\mathrm{C}_{19} \mathrm{H}_{34} \mathrm{LiO}_{2}$ & {$[\mathrm{ML}+\mathrm{Li}]^{+}$} \\
303 & 303.2874 & 303.2870 & -1.3 & $\mathrm{C}_{19} \mathrm{H}_{36} \mathrm{LiO}_{2}$ & {$[\mathrm{ME}+\mathrm{Li}]^{+} /[\mathrm{MO}+\mathrm{Li}]^{+}$} \\
317 & 317.2669 & 317.2662 & -2.2 & $\mathrm{C}_{19} \mathrm{H}_{34} \mathrm{LiO}_{3}$ & {$[\mathrm{ML}+\mathrm{O}+\mathrm{Li}]^{+}$} \\
319 & 319.2824 & 319.2819 & -1.6 & $\mathrm{C}_{19} \mathrm{H}_{36} \mathrm{LiO}_{3}$ & {$[\mathrm{ME}+\mathrm{O}+\mathrm{Li}]^{+} /[\mathrm{MO}+\mathrm{O}+\mathrm{Li}]^{+}$} \\
333 & 333.2618 & 333.2612 & -1.8 & $\mathrm{C}_{19} \mathrm{H}_{34} \mathrm{LiO}_{4}$ & {$[\mathrm{ML}+2 \mathrm{O}+\mathrm{Li}]^{+}$} \\
335 & 335.2771 & 335.2768 & -0.9 & $\mathrm{C}_{19} \mathrm{H}_{36} \mathrm{LiO}_{4}$ & {$[\mathrm{ME}+2 \mathrm{O}+\mathrm{Li}]^{+} /[\mathrm{MO}+2 \mathrm{O}+\mathrm{Li}]^{+}$} \\
351 & 351.2717 & 351.2717 & 0.0 & $\mathrm{C}_{19} \mathrm{H}_{36} \mathrm{LiO}_{5}$ & {$[\mathrm{ME}+3 \mathrm{O}+\mathrm{Li}]^{+} /[\mathrm{MO}+3 \mathrm{O}+\mathrm{Li}]^{+}$} \\
351 & 351.3084 & 351.3081 & -0.9 & $\mathrm{C}_{20} \mathrm{H}_{40} \mathrm{LiO}_{4}$ & {$[\mathrm{ME}+\mathrm{CH}+\mathrm{OH}+\mathrm{Li}]^{+} /[\mathrm{MO}+\mathrm{O}+$} \\
& & & & \\
379 & 379.3038 & 379.3030 & -2.1 & $\mathrm{C}_{21} \mathrm{H}_{40} \mathrm{LiO}_{3}$ & {$[\mathrm{OH}+\mathrm{Li}]^{+}$} \\
503 & 503.3926 & 503.3918 & -1.6 & $\mathrm{C}_{29} \mathrm{H}_{52} \mathrm{LiO}_{6}$ & {$[\mathrm{OL}+\mathrm{D}+\mathrm{Li}]^{+}$} \\
505 & 505.4084 & 505.4075 & -1.8 & $\mathrm{C}_{29} \mathrm{H}_{54} \mathrm{LiO}_{6}$ & {$[\mathrm{Li}]^{+}$} \\
505 & 505.4266 & 505.4261 & -1.0 & $\left.\mathrm{C}_{30} \mathrm{H}_{58} \mathrm{LiO}_{3} \mathrm{~S}+\mathrm{Li}\right]^{+} /[\mathrm{MO}+\mathrm{D}+\mathrm{Li}]^{+}$ \\
505 & 505.4623 & 505.4625 & 0.4 & $\mathrm{C}_{31} \mathrm{H}_{62} \mathrm{LiO}_{2} \mathrm{~S}$ & {$[\mathrm{LA}+\mathrm{O}+\mathrm{DT}+\mathrm{Li}]^{+}$} \\
507 & 507.4421 & 507.4418 & -0.6 & $\mathrm{C}_{30} \mathrm{H}_{60} \mathrm{LiO}_{3} \mathrm{~S}$ & {$[\mathrm{ME}+\mathrm{DT}+\mathrm{Li}]^{+} /[\mathrm{MO}+\mathrm{DT}+\mathrm{Li}]^{+}$} \\
519 & 519.4423 & 519.4418 & -1.0 & $\mathrm{C}_{31} \mathrm{H}_{60} \mathrm{LiO}_{3} \mathrm{~S}$ & {$[\mathrm{EA}+\mathrm{O}+\mathrm{DT}+\mathrm{Li}]^{+} /[\mathrm{OA}+\mathrm{O}+\mathrm{DT}+\mathrm{Li}]^{+}$} \\
521 & 521.4583 & 521.4574 & -1.7 & $\mathrm{C}_{31} \mathrm{H}_{62} \mathrm{LiO}_{3} \mathrm{~S}$ & {$[\mathrm{ML}+\mathrm{O}+\mathrm{DT}+\mathrm{Li}]^{+}$} \\
535 & 535.4373 & 535.4367 & -1.1 & $\mathrm{C}_{31} \mathrm{H}_{60} \mathrm{LiO}_{4} \mathrm{~S}$ & {$[\mathrm{ME}+\mathrm{O}+\mathrm{DT}+\mathrm{Li}]^{+} /[\mathrm{MO}+\mathrm{O}+\mathrm{DT}+\mathrm{Li}]^{+}$} \\
537 & 537.4521 & 537.4523 & -0.6 & $\mathrm{C}_{31} \mathrm{H}_{62} \mathrm{LiO}_{4} \mathrm{~S}$ & {$[\mathrm{ME}+2 \mathrm{O}+\mathrm{DT}+\mathrm{Di}+\mathrm{Li}]^{+} /[\mathrm{MO}+2 \mathrm{O}+\mathrm{DT}+\mathrm{Li}]^{+}$}
\end{tabular}
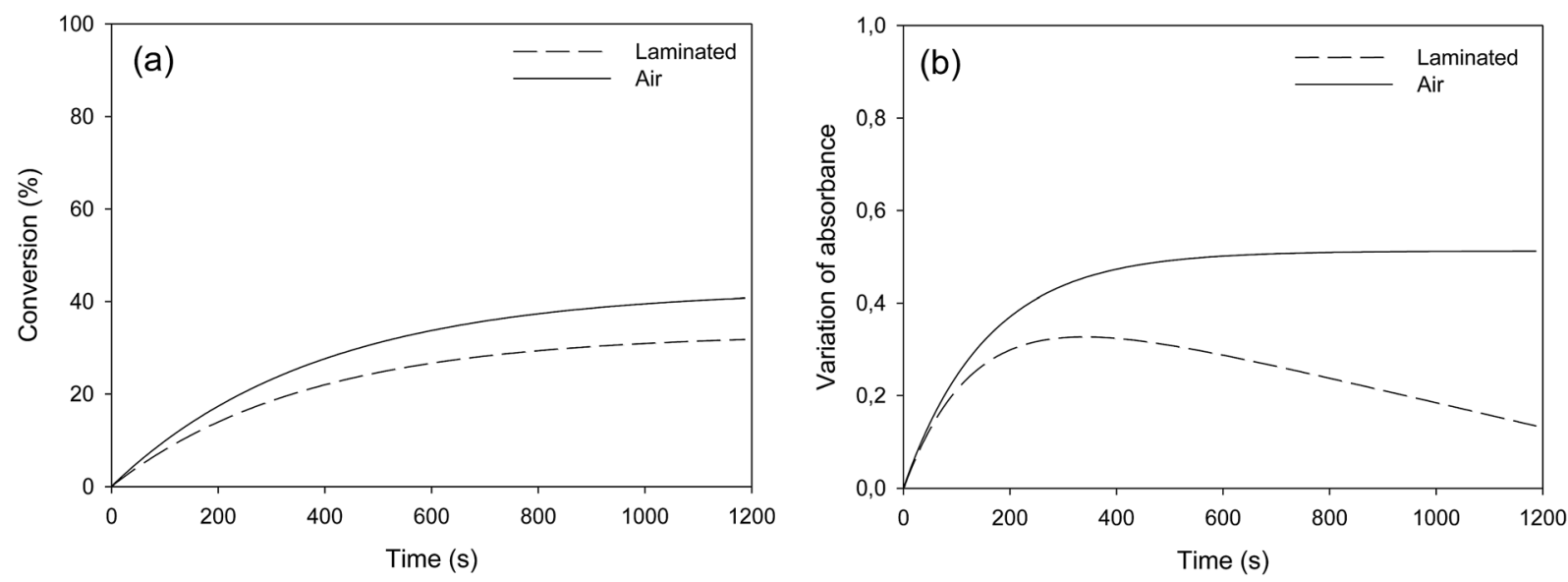

Fig. 3 Photo-oxidation kinetic study of methyl oleate: evolution of (a) double bond conversion and (b) $\mathrm{OH}$ absorbance variation $-\mathrm{T}=30{ }^{\circ} \mathrm{C}$, polychromatic light $\left(I_{0}=120 \mathrm{~mW} \mathrm{~cm}^{-2}\right.$ at $\left.365 \mathrm{~nm}\right)$.

formation of hydroperoxides could be the cause of the plateau observed after $500 \mathrm{~s}$ irradiation.

Identical oxidation processes were observed for methyl elaidate. However, the reaction rate was slower compared to MO (see Fig. SI. 2 in ESI $\dagger$ ). These results could be explained by the presence of methyl linoleate in MO sample, which could accelerate the (hydro)peroxide formation rate as described by other scientists. ${ }^{20,22}$

Then, high resolution mass spectrometry analysis of the irradiated fatty esters solubilized into a LiI solution was carried out in order to confirm or determine the structure of the different oxidized products. Fig. 5 presents the mass spectra of ME after different irradiation times under air (see Fig. SI.3 in $\mathrm{ESI} \dagger$ for MO). Table 1 lists the main products identified by ESIMS experiments and Fig. 6 depicts some of possible chemical structures.
Some oxidation products of MO and ME were detected at $\mathrm{m} / \mathrm{z}$ 319.2824, $\mathrm{m} / \mathrm{z} 335.2771, \mathrm{~m} / \mathrm{z} 351.2717$ and labeled as $[\mathrm{M}+\mathrm{O}+$ $\mathrm{Li}]^{+}$(with $\mathrm{M}=\mathrm{MO}$ or $\mathrm{ME}$ ), $[\mathrm{M}+2 \mathrm{O}+\mathrm{Li}]^{+}$, and $[\mathrm{M}+3 \mathrm{O}+\mathrm{Li}]^{+}$, respectively, according to West et al. ${ }^{23}$ The abundance of these ions increased as a function of irradiation time. The $\mathrm{m} / \mathrm{z}$ 319.2824 corresponds to the lithium adduct of mono-oxidized ester while $\mathrm{m} / \mathrm{z} 335.2771$ could correspond to hydroperoxide $^{24-26}$ and $m / z 351.2717$ to trioxidized ester, either in monozonide or trioxolan form (Fig. 6). Trioxidized species could result from ozonolysis of the unsaturated fatty esters. Indeed, the singlet oxygen ${ }^{1} \mathrm{O}_{2}$ resulting from the photodecomposition of hydroperoxides can react under UV with the triplet oxygen ${ }^{3} \mathrm{O}_{2}$ to produce $\mathrm{O}_{3} \cdot{ }^{27-33}$ Note that the high resolving power of the time of flight instrument operating in the $\mathrm{W}$ reflectron mode permitted to separate the $\mathrm{m} / \mathrm{z} 351.2717$ ion which is a lowabundant species and the lithium adduct of the side product 


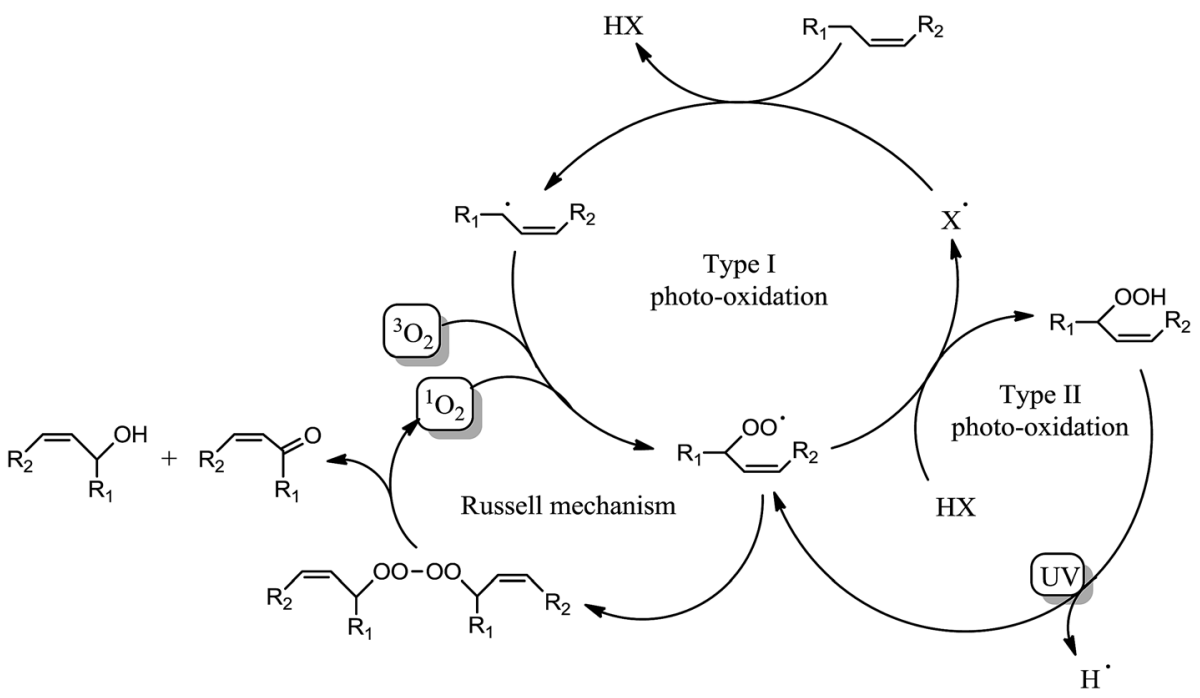

Fig. 4 Photo-oxidation mechanisms of olefins.

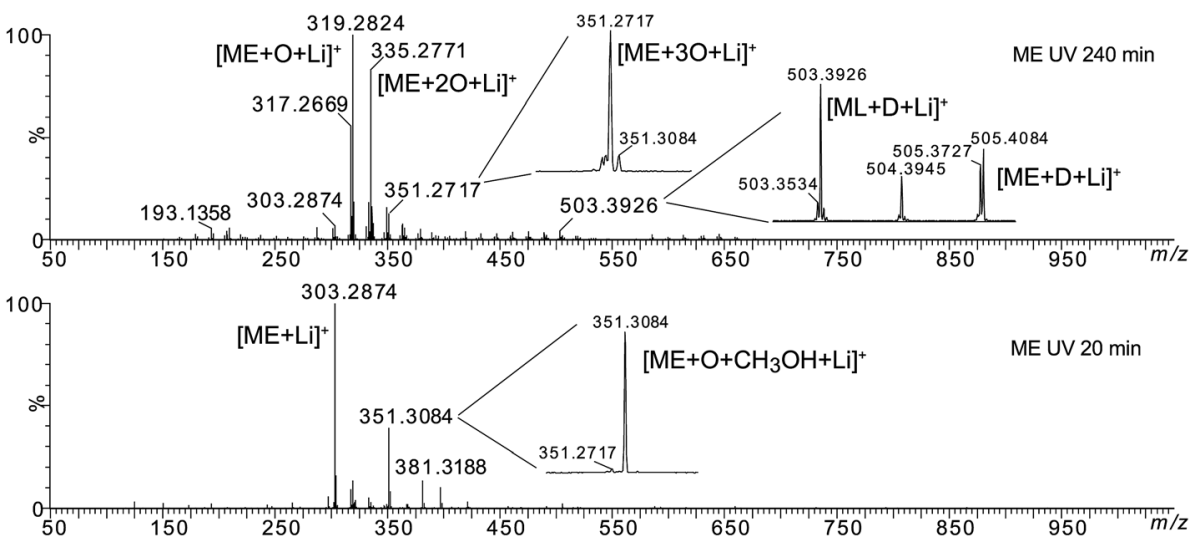

Fig. 5 HRMS spectra of methyl elaidate after different UV irradiation times under air.

at $m / z 351.3084$ previously described. Bishydroxyperoxide ions were too low-abundant species to be discussed.

The MS/MS spectrum of $m / z 335.2771$ shows product ions at $\mathrm{m} / \mathrm{z} 317.2669$ and $\mathrm{m} / \mathrm{z} 299.2568$ resulting from the loss of one or two $\mathrm{H}_{2} \mathrm{O}$ molecules, respectively, but also product ion at $\mathrm{m} / \mathrm{z}$ 303.2874 which results from the loss of an $\mathrm{O}_{2}$ molecule (Fig. SI.4 in ESI $\dagger$ ). More interestingly, the product ions $\mathrm{m} / \mathrm{z} 207.1504, \mathrm{~m} / \mathrm{z}$ 193.1358 and $m / z \quad 179.1205$ correspond to $\mathrm{C}_{11} \mathrm{H}_{20} \mathrm{LiO}_{3}$, $\mathrm{C}_{10} \mathrm{H}_{18} \mathrm{LiO}_{3}$ and $\mathrm{C}_{9} \mathrm{H}_{16} \mathrm{LiO}_{3}$, i.e. to lithium adducts of methyl 10oxodecanoate, methyl 9-oxononanoate and methyl 8-oxooctanoate, respectively. Such results indicate that $m / z 335.2771$ was a mixture of isomers of either diol or hydroperoxide structures (Fig. SI.4b in ESI $\dagger$ ) and that oxidation more probably occurred on the $\mathrm{C}_{10}, \mathrm{C}_{9}$ and $\mathrm{C}_{8}$ atoms of the fatty chain.

The MS/MS spectrum of $m / z 351$ (which is a relatively lowabundance ion) shows abundant product ions at $\mathrm{m} / \mathrm{z} 319.2824$ and $m / z 301.2719$ resulting from the successive losses of $\mathrm{CH}_{3} \mathrm{OH}$ and $\mathrm{H}_{2} \mathrm{O}$ molecules (data not shown). Note that this MS/MS spectrum presents the product ions of both precursors $\mathrm{m} / \mathrm{z}$ $351.2717[\mathrm{M}+3 \mathrm{O}+\mathrm{Li}]^{+}$and $m / z 351.3084\left[\mathrm{M}+\mathrm{O}+\mathrm{CH}_{3} \mathrm{OH}+\mathrm{Li}\right]^{+}$.
Indeed, these isobaric species cannot be separated by quadrupole selection. The loss of $\mathrm{H}_{2} \mathrm{O}$ can arise from either the trioxidized ester and/or of the side-product. On the other hand, the loss of methanol is more probable from the side product.

Besides the series of $\mathrm{m} / \mathrm{z} 319.2824, \mathrm{~m} / \mathrm{z} 335.2771$ and $\mathrm{m} / \mathrm{z}$ 351.2717 , other photo-oxidized fatty esters corresponding to lithium adducts of oxidized linoleate were detected at $\mathrm{m} / \mathrm{z}$ 317.2669 and $m / z 333.2618$ (Fig. 5). Then, low-abundance ions appeared in the $m / z 450$ to 650 range of the mass spectra (Fig. 5). Most of them could be attributed to aggregates generated in the ESI source. Indeed, these dimers gave the corresponding monomer lithium adducts when LC-MS/MS analyses were performed (data not shown). However, few of them were confidently attributed to covalent structures between methyl ester (MO/ME ( $m / z 505.4084)$ or ML ( $m / z$ 503.3926)) and zwitterion $\mathrm{D}$ as confirmed by MS/MS analyses (see Fig. SI. 5 in ESI $\dagger$ for $m / z$ 505). Indeed, trioxolan species can decompose into several zwitterions and aldehydes (depicted in Fig. 7). It can also be noticed on the ${ }^{1} \mathrm{H}$ NMR spectra a singlet at $9 \mathrm{ppm}$ that could be attributed to aldehyde proton. 


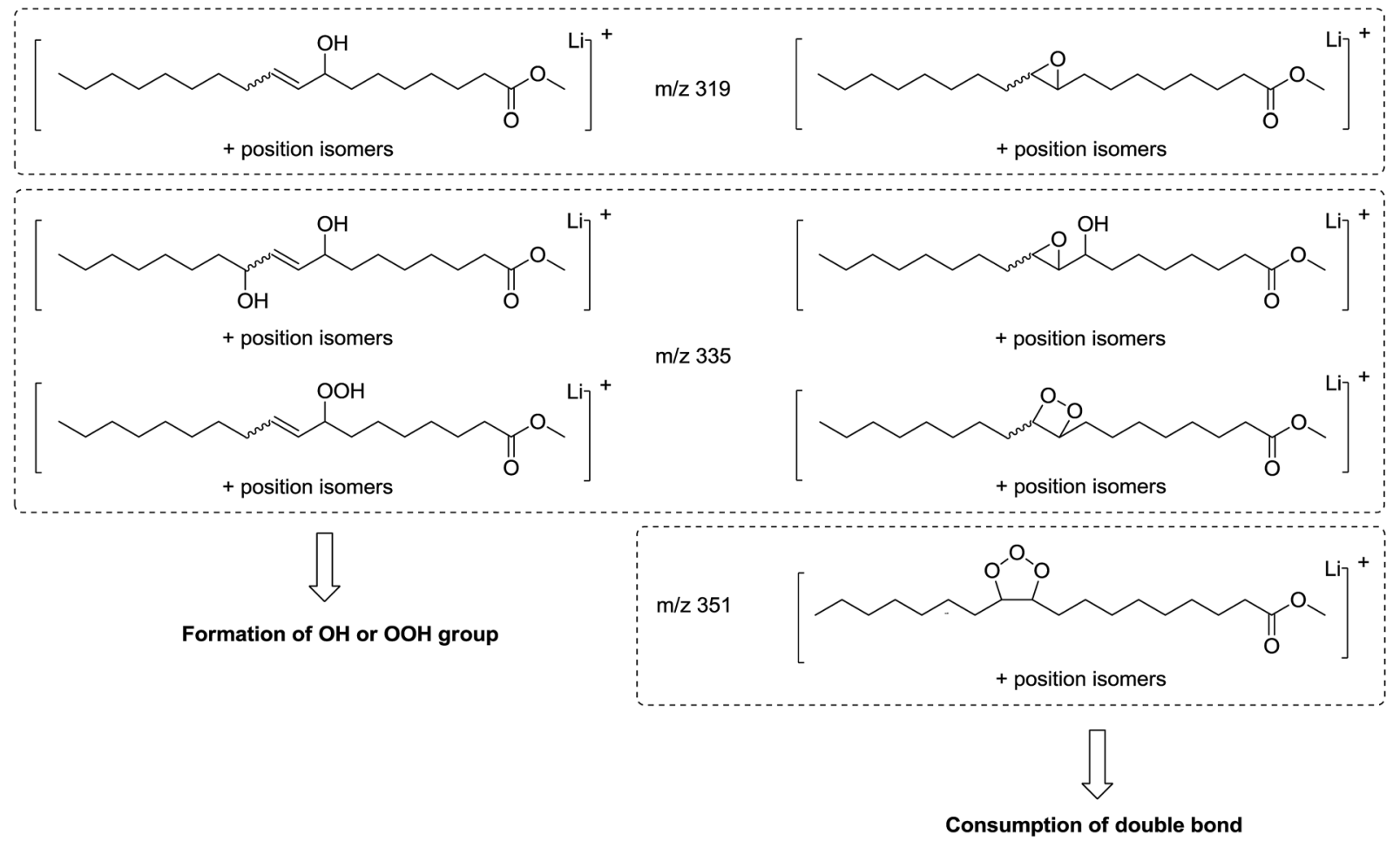

Fig. 6 Possible chemical structures of molecular ions at $\mathrm{m} / \mathrm{z} 319,335$ and 351 resulting from methyl oleate oxidation.

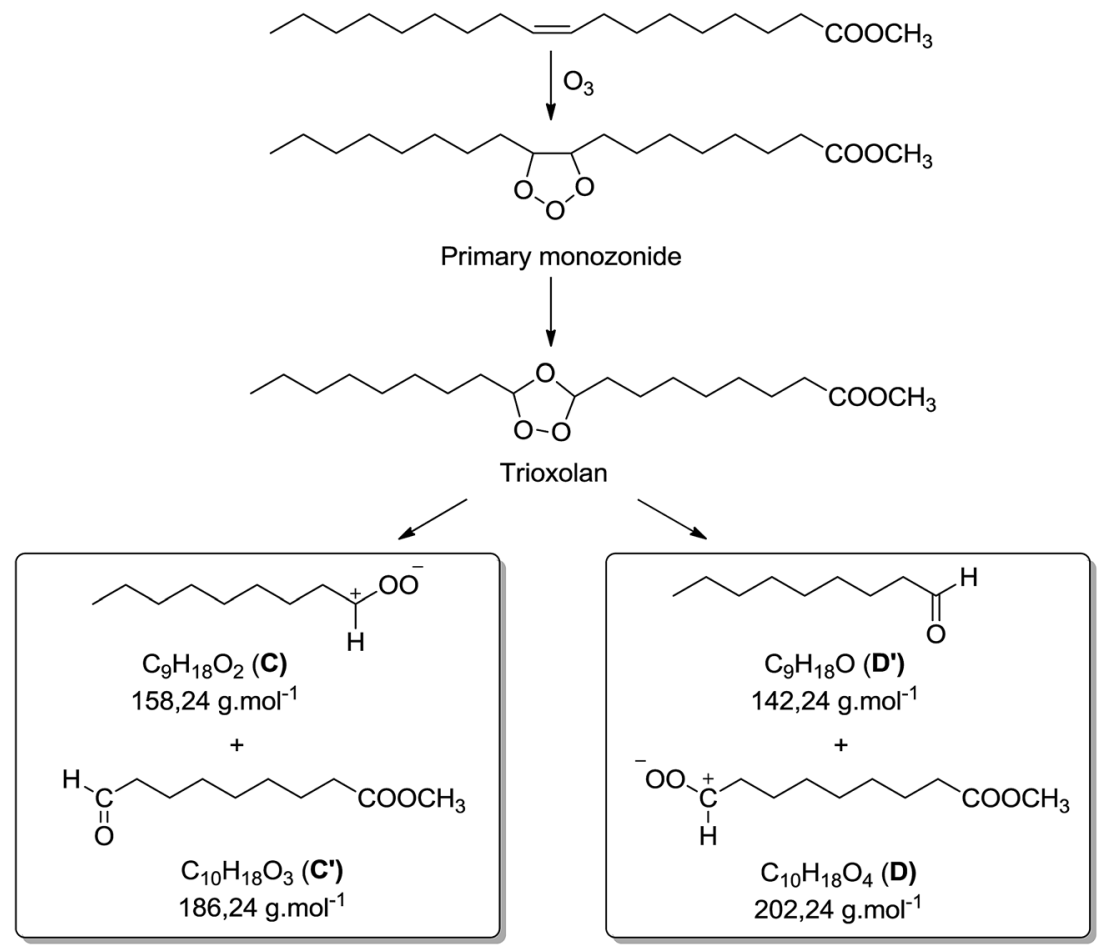

Fig. 7 Chemical structures of products resulting from methyl oleate or elaidate ozonolysis.

Comparing ME and MO sample reactivity (Fig. 5 and SI. $3 \dagger$ ), we note that more products were formed and that reaction rate was higher in the case of MO for the reason previously mentioned (presence of methyl linoleate).
Thus, both techniques permitted to observe photo-oxidation products of unsaturated fatty esters under UV and air, in accordance with literature: ${ }^{23-26}$ hydroperoxides $(\mathrm{m} / \mathrm{z} 335.2771$ and $m / z 333.2618)$, mono-oxidized esters $(\mathrm{m} / \mathrm{z} 319.2824$ and $\mathrm{m} / \mathrm{z}$ 
317.2669) which could be hydroxylated or epoxidized ME/MO and $\mathrm{ML}$, well known as side oxidation products resulting from the hydroperoxide decomposition, and trioxidized esters $(\mathrm{m} / \mathrm{z}$ $351.2717) . .^{33}$ The formation of covalent bond between unsaturated fatty ester and zwitterionic species constitutes an important point. Indeed, it is possible to envisage such intermolecular covalent coupling when photo-oxidation is transposed to triglyceride molecules. Moreover, the increase of the unsaturation degree could enhance the probability of oxidative crosslinking.

\section{Photoinitiated thiol-ene reaction of fatty esters under air}

Reaction media containing methyl stearate and dodecanethiol were first submitted to UV irradiation. As expected, no product of thiol addition was detected using either IR, ESI-MS or GC-MS, meaning that saturated methyl ester did not react with dodecanethiol (DT). Then, MS and IR investigations were performed on methyl fatty esters (MO or ME) irradiated in the presence of 0.5 equivalent DT (conditions for reaching fatty double bond conversion higher than $80 \%) .{ }^{4}$ Although an absorption band corresponding to the $\mathrm{S}-\mathrm{H}$ bond at $2550 \mathrm{~cm}^{-1}$ can be observed on the IR spectra, its low intensity did not allow accurately calculating the thiol conversion. Nonetheless, its entire consumption was observed in the whole following experiments after $5 \mathrm{~min}$ of irradiation. Hence, only the double bond conversion kinetics and the $\mathrm{OH}$ absorbance variation were presented here. Besides, as similar kinetics was observed in aerated and laminated conditions, only experiments carried out under air are presented Fig. 8.

As expected, double bond consumption was faster in the presence of dodecanethiol, compared to our previous results obtained on the sole unsaturated fatty esters (Fig. 8a). Nonetheless, the comparison of the $\mathrm{OH}$ absorbance variation curves obtained with and without dodecanethiol shows a competition between the oxidation and the thiol-ene addition (Fig. 8b). This competition seems in favor to the oxidation addition at the beginning of the reaction. After $10 \mathrm{~min}$ irradiation, the thiolene prevailed. For ME, the same competition could be observed even though less pronounced (see Fig. SI.6 in ESI $\dagger$ ).
GC-MS analyses of irradiated reaction media (MO or ME with DT) show, depending on reaction time, the presence of unreacted methyl esters $\left(\mathrm{m} / \mathrm{z} 296.2787, t_{\mathrm{R}} 17.8 \mathrm{~min}\right)$, unreacted DT (RSH, $m / z 202.1757, t_{\mathrm{R}} 11.9 \mathrm{~min}$ ), oxidized DT (RS-SR $\mathrm{m} / z$ $\left.402.3375, t_{\mathrm{R}} 27.3 \mathrm{~min}\right)$ and the expected thiol-ene adduct $(\mathrm{m} / \mathrm{z}$ 498.4426, $t_{\mathrm{R}} 27.3 \mathrm{~min}$ ) (see Fig. SI.7a in ESI $\dagger$ for ME). These identifications were verified by accurate mass measurements. The EI mass spectra shows that the thiol-ene adduct was a mixture of two regioisomers with the sulfur atom linked to either the 9 or the 10 carbon of the fatty chain (see Fig. SI.7b in ESI $\dagger)$. Characteristic fragment ions of the $1^{\text {st }}$ regioisomer $(\mathrm{m} / \mathrm{z}$ 341 and $m / z 371$ for $\mathrm{C}_{9}$ branching) and of the $2^{\text {nd }}$ regioisomer $\left(\mathrm{m} / \mathrm{z} 327\right.$ and $\mathrm{m} / \mathrm{z} 385$ for $\mathrm{C}_{10}$ branching) correspond to $\alpha$ cleavages from $\mathbf{M}^{+\cdot}$ when charge (and odd electron) is localized on sulfur atom, in accordance with previous data. ${ }^{34}$ Note that in our chromatographic conditions, the two regioisomers were only partially separated as shown in the extracted ion chromatograms in Fig. SI.7a. $\dagger$

ESI-MS analyses of the irradiated thiol/ene formulation solubilized in the LiI solution were carried out in order to characterize this competition. Fig. 9 presents ESI-MS spectra of the reaction medium containing ME with dodecanethiol after different irradiation times (see Fig. SI.8 in ESI† for methyl oleate).

The lithium adducts of the mono- and di-oxidized $(\mathrm{m} / \mathrm{z}$ 319.2824 and $m / z 335.2771)$ or non oxidized $(\mathrm{m} / \mathrm{z} 303.2874)$ fatty esters were observed. The abundance of $\mathrm{m} / \mathrm{z} 303.2874$ decreased when irradiation time increased while the abundance of oxidized forms increased. Then, we can note the emergence of ions at $\mathrm{m} / \mathrm{z} 505.4623, \mathrm{~m} / \mathrm{z} 521.4583$ and $\mathrm{m} / \mathrm{z} 537.4521$ after $20 \mathrm{~min}$ irradiation, the $\mathrm{m} / \mathrm{z} 521.4583$ becoming the most abundant species at $60 \mathrm{~min}$ irradiation. The elemental composition of these ions was consistent with thiol-ene adducts (Table 1): $\mathrm{m} / \mathrm{z} 505.4623$ could correspond to the expected adduct $[\mathrm{ME}+\mathrm{DT}+\mathrm{Li}]^{+}$while $\mathrm{m} / \mathrm{z} 521.4583$ and $\mathrm{m} / \mathrm{z}$ 537.4521 were consistent with photoadducts of mono- ([ME + O $\left.+\mathrm{DT}+\mathrm{Li}]^{+}\right)$and di-oxidized esters $\left([\mathrm{ME}+2 \mathrm{O}+\mathrm{DT}+\mathrm{Li}]^{+}\right)$. Note that besides $m / z 505.4623$, two other ions of low-abundance could be detected at $\mathrm{m} / \mathrm{z} 505.4084$ and $\mathrm{m} / \mathrm{z} 505.4266$ (insets of
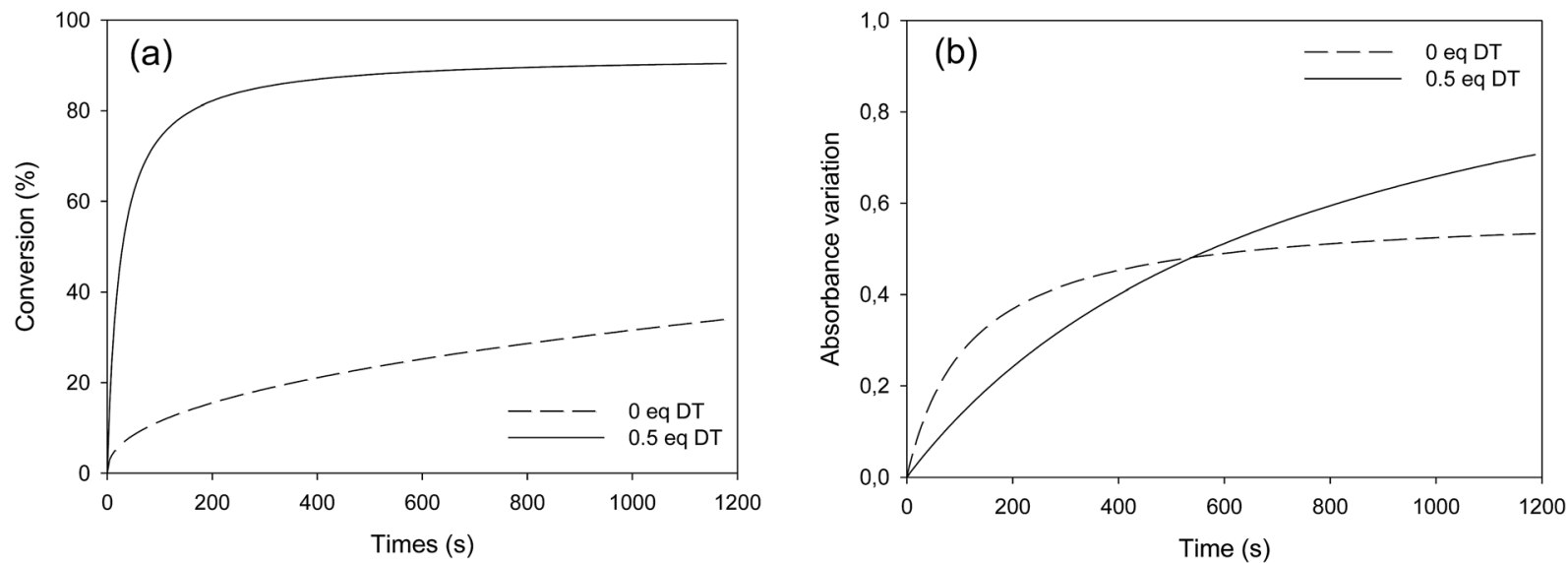

Fig. 8 Comparison of photoinitiated thiol-ene kinetics of methyl oleate in the presence or not of 0.5 equivalent SH: evolution of (a) double bond conversion and (b) $\mathrm{OH}$ absorbance variation $-T=30^{\circ} \mathrm{C}$, polychromatic light $\left(I_{0}=120 \mathrm{~mW} \mathrm{~cm}^{-2}\right.$ at $\left.365 \mathrm{~nm}\right)$. 


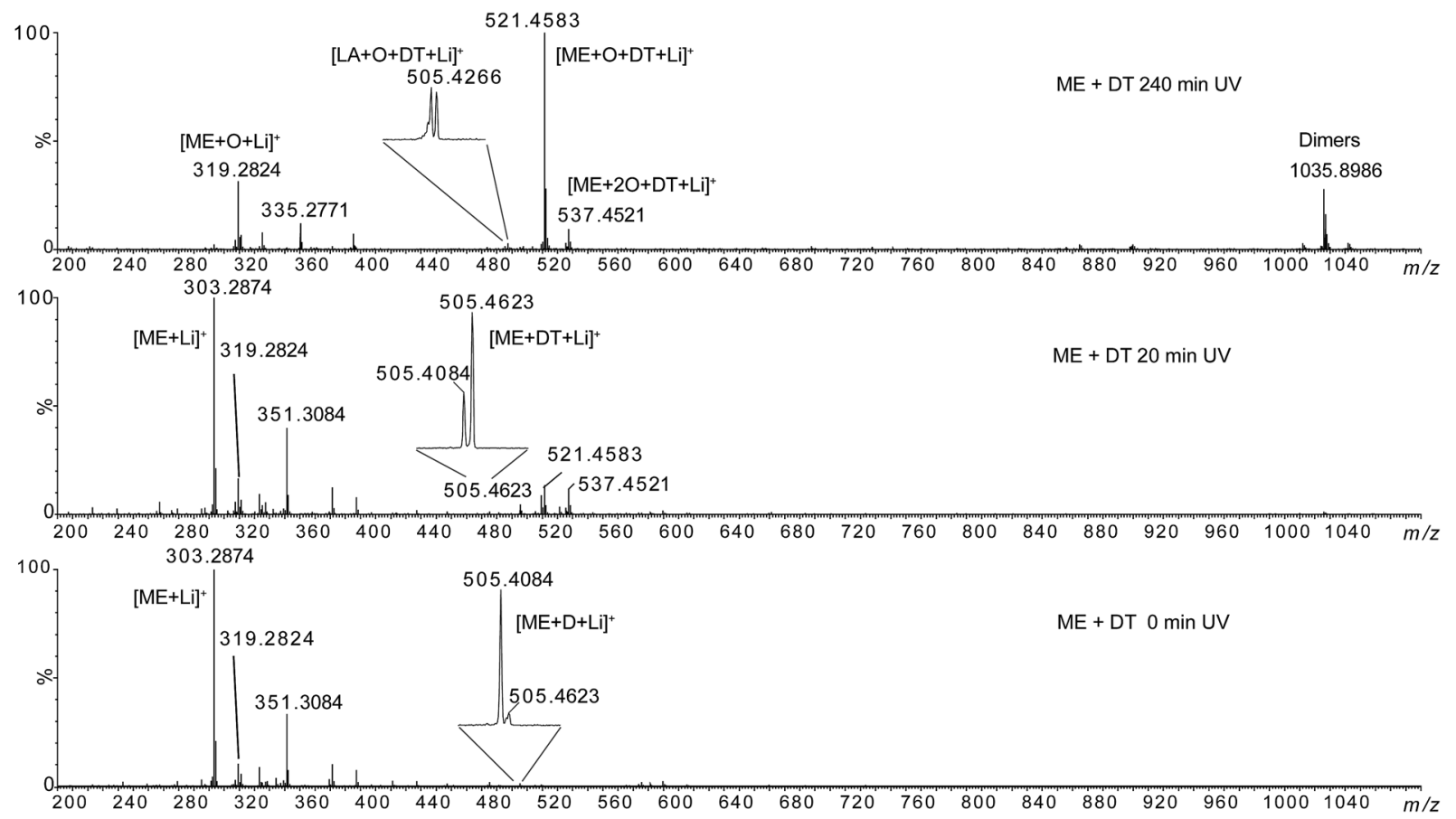

Fig. 9 HRMS spectra of methyl elaidate +0.5 eq. dodecanethiol at $0 \mathrm{~min}, 20 \mathrm{~min}$ and $240 \mathrm{~min}$ UV irradiation.

Fig. 9 and Table 1). These ones could correspond to the covalent adduct of methyl ester and zwitterion $\mathrm{D}[\mathrm{ME}+\mathrm{D}+$ $\mathrm{Li}^{+}\left(\mathrm{m} / z\right.$ 505.4084) $\left(\mathrm{C}_{29} \mathrm{H}_{54} \mathrm{LiO}_{6}\right)$ (Fig. SI.5b $\dagger$ ), and to the thiol-ene adduct of residual oxidized linoleic acid and dodecanethiol $[\mathrm{LA}+\mathrm{O}+\mathrm{DT}+\mathrm{Li}]^{+}(\mathrm{m} / \mathrm{z}$ 505.4266) $\left(\mathrm{C}_{30} \mathrm{H}_{58} \mathrm{LiO}_{3} \mathrm{~S}\right)$, respectively. The thiol-ene adduct between residual oxidized oleic acid and dodecanethiol [OA + O + DT + $\mathrm{Li}^{+}\left(\mathrm{C}_{30} \mathrm{H}_{60} \mathrm{LiO}_{3} \mathrm{~S}\right)$ was also detected at $\mathrm{m} / z$ 507.4421, confirming that thiol-ene addition can occur on oxidized fatty acids. Note that the relative abundance of these ions varied with irradiation time (insets of Fig. 9). Thus, $m / z 505.4623$ became the most abundant ion at 20 min irradiation for ME.

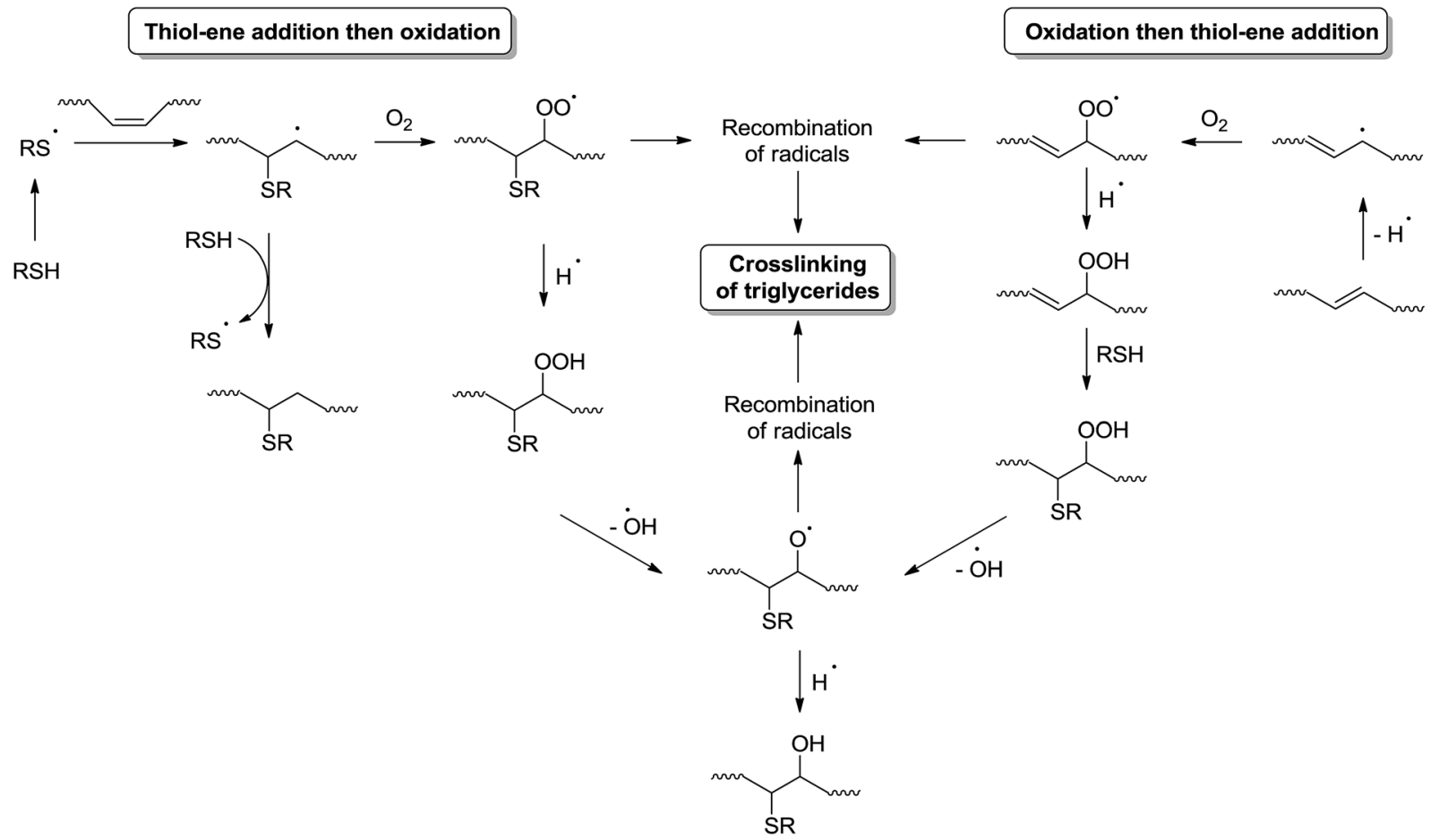

Fig. 10 Proposed mechanisms for the photoinitiated thiol-ene addition under air. 
In addition, oxidation of thiol-ene adduct can explain the decrease of $\mathrm{m} / \mathrm{z} 505.4623$ relatively to $\mathrm{m} / \mathrm{z} 505.4266$. Thiol-ene adducts of oxidized linoleate were very low-abundant species that were detected at $\mathrm{m} / \mathrm{z} 519.4423$ and $\mathrm{m} / \mathrm{z} 535.4373$ (Table 1). Lastly, note that ions of high $\mathrm{m} / \mathrm{z}$ values (such as $\mathrm{m} / \mathrm{z}$ 1035.8986) corresponded to non-covalent dimer species formed during the ESI process as verified by LC-ESI-MS experiments (for example, the extracted ion chromatograms of $m / z 1035.8986$ and $m / z 521.4583$ were superimposed (data not shown)).

Then, MS/MS analyses of $\mathrm{m} / z$ 505.4623, $\mathrm{m} / \mathrm{z} 521.4583$ and $\mathrm{m} / \mathrm{z}$ 537.4521 were carried out (see Fig. SI.9 in ESI $\dagger$ ). In the case of the $\mathrm{m} / \mathrm{z} 505.4$, ion mobility separation before the collision activation was required to achieve specific MS/MS analysis. Indeed, isobaric $\mathrm{m} / \mathrm{z} 505.4266$ and $\mathrm{m} / \mathrm{z} 505.4623$ ions cannot be separated by the quadrupole mass analyser used for ion selection (see Experimental section for details). The MS/MS spectrum of $\mathrm{m} / \mathrm{z} 505.4623$ shows exclusively product ion at $\mathrm{m} / \mathrm{z}$ 303.2874 corresponding to $\mathrm{C}_{12} \mathrm{H}_{26} \mathrm{~S}$ loss while MS/MS spectra of $\mathrm{m} / z 521.4583$ and $m / z 537.4521$ shows $218 \mathrm{u}\left(\mathrm{C}_{12} \mathrm{H}_{26} \mathrm{SO}\right)$ and 168 $\mathrm{u}\left(\mathrm{C}_{12} \mathrm{H}_{24}\right)$ losses.

All these dissociation patterns confirm the thiol-ene addition onto non oxidized and also oxidized fatty ester. So thiolene addition and oxidation could well concomitantly exist, as summarized in Fig. 10.

\section{Conclusions}

Photo-oxidation and photoinitiated thiol-ene addition applied to fatty unsaturated esters were investigated. Complementary infrared spectroscopy and mass spectrometry analyses show that numerous possible reactions involving fatty esters, thiol molecule and oxygen could occur. Besides the expected classical thiol-ene addition, oxidation of the fatty moieties could occur during the photochemical step. Thus, peroxydation could take place directly on unsaturated fatty molecules as well as on thiolene adducts, whereas thiol-ene addition could also occur directly on unsaturated fatty acid or on oxidized fatty moieties. In addition, the recombination of peroxyl radicals as well as the reaction between intermediate zwitterionic species (coming from fatty double bond ozonolysis) and fatty moieties could explain the formation of intermolecular covalent bonds between fatty esters. It could be noticed that no propagation of the radical thiol-ene addition to fatty double bonds was highlighted. Nonetheless, extending all these results to vegetable oils, the identified reactions could be responsible of the triglycerides crosslinking during the photoinitiated thiol-ene process, even in the presence of a monothiol. Finally, the preoxidation of triglycerides could be beneficial to prepare coatings by the thiol-ene process.

\section{Acknowledgements}

We thank the Labex SynOrg (ANR-11-LABX-0029), the European Regional Development Fund (ERDF 31708) and the French Government (MESR fellowship) for financial support.

\section{Notes and references}

1 S. Caillol, M. Desroches, S. Carlotti, R. Auvergne and B. Boutevin, Green Mater., 2013, 1, 16.

2 P. Alagi, Y. J. Choi, J. Seog and S. C. Hong, Ind. Crops Prod., 2016, 87, 78.

3 U. Bexell, M. Olsson, M. Johansson and P. Sundell, Surf. Coat. Technol., 2003, 166, 141.

4 Y. H. Zhao, D. Vuluga, L. Lecamp and F. Burel, Prog. Org. Coat., 2016, 101, 216.

5 M. Desroches, S. Caillol, V. Lapinte, R. Auvergne and B. Boutevin, Macromolecules, 2011, 44, 2489.

6 M. Desroches, S. Caillol, R. Auvergne and B. Boutevin, Eur. J. Lipid Sci. Technol., 2012, 114, 84.

7 M. Ionescu, D. Radojcic, X. Wan, Z. S. Petrovic and T. A. Upshaw, Eur. Polym. J., 2015, 67, 439.

8 G. B. Bantchev, J. A. Kenar, G. Biresaw and M. G. Han, J. Agric. Food Chem., 2009, 57, 1282.

9 J. Justynska, Z. Hordyjewicz and H. Schlaad, Polymer, 2005, 46, 12057.

10 O. Zovi, L. Lecamp, C. Loutelier-Bourhis, C. M. Lange and C. Bunel, Eur. J. Lipid Sci. Technol., 2011, 113, 616.

11 D. Oursel, C. Loutelier-Bourhis, N. Orange, S. Chevalier, V. Norris and C. M. Lange, Rapid Commun. Mass Spectrom., 2007, 21, 1.

12 O. Zovi, L. Lecamp, C. Loutelier-Bourhis, C. M. Lange and C. Bunel, Green Chem., 2011, 13, 1014.

13 K. Giles, S. D. Pringle, K. R. Worthington, D. Little, J. L. Wildgoose and R. H. Bateman, Rapid Commun. Mass Spectrom., 2004, 18, 2401.

14 S. E. Slade, K. Thalassinos, R. H. Bateman, M. T. Bowers and J. H. Scrivens, Int. J. Mass Spectrom., 2007, 261, 1.

15 K. Peter, C. Vollhardt and N. E. Schore, Traité de chimie organique, De Boeck, 4th edn, 1990, p. 639.

16 J. H. Gross, Mass Spectrometry - A Textbook, Springer, 2nd edn, 2011, p. 198.

17 A. Greer, Acc. Chem. Res., 2006, 39, 797.

18 F. Bosca, M. A. Miranda, I. M. Morera and A. Samadi, J. Photochem. Photobiol., B, 2000, 58, 1.

19 A. W. Girotti, Photochem. Photobiol., 1990, 51, 497.

20 J. Regensburger, T. Maisch, A. Knak, A. Gollmer, A. Felgenträger, K. Lehner and W. Bäumler, Phys. Chem. Chem. Phys., 2013, 15, 17672.

21 J. Regensburger, A. Knak, T. Maisch, L. Landthaler and W. Bäumler, Exp. Dermatol., 2011, 21, 135.

22 D. A. Pratt, K. A. Tallman and N. A. Porter, Acc. Chem. Res., 2011, 44, 458.

23 R. E. West, R. K. Marvin, K. Hensley and D. Isailovic, Int. J. Mass Spectrom., 2014, 372, 29.

24 D. B. Min T. H. Smouse, Flavor chemistry offats and oils, Am. Oil Chem. Soc., Champaign, IL, 1985, p. 1.

25 A. M. Wilcox and L. J. Marnett, Chem. Res. Toxicol., 1993, 6, 413.

26 G. G. Pereira, R. M. Alberici, G. D. Fernandes, I. B. S. Cunha, M. N. Eberlin, M. C. Dobarganes, R. J. Daroda and D. Barrera-Arellano, Eur. J. Lipid Sci. Technol., 2014, 116, 952. 
27 W. W. Christie, Lipid Analysis, The Oil Press, Bridgewater, UK, 3rd edn, 2003.

28 E. N. Frankel, R. F. Garwood, B. P. S. Khambay, G. P. Moss and B. C. L. Weedon, J. Chem. Soc., Perkin Trans. 1, 1984, 1, 2233.

29 L. Rebrovic, J. Am. Oil Chem. Soc., 1992, 69, 160.

30 O. Vesna, S. Sjogren, E. Weingartner, V. Samburova, M. Kalberer, H. W. Gäggeler and M. Amman, Atmos. Chem. Phys., 2008, 8, 4683.
31 S. Warwell and M. R. Klaas, Lipid Technol., 1997, 9, 10.

32 S. T. Bairai and D. H. Stedman, J. Geophys. Res.: Atmos., 1992, 97, 109.

33 S. H. J. Brown, T. W. Mitchell and S. J. Blanksby, Biochim. Biophys. Acta, 2011, 1811, 807.

34 A. Sammaiah, K. V. Padmaja and R. B. N. Prasad, Eur. J. Lipid Sci. Technol., 2016, 118, 495. 